\title{
Interactive comment on "Reconstruction of flow conditions from 2004 Indian Ocean tsunami deposits at the Phra Thong island using a deep neural network inverse model" by Rimali Mitra et al.
}

\section{Rimali Mitra et al.}

mitra.rimali.37z@st.kyoto-u.ac.jp

Received and published: 5 January 2021

We thank the reviewer for the insightful assessment of our manuscript and for the numerous comments and suggestions. We have already provided the logical reasoning to the comments that reviewers suggested. However, while analyzing the detailed natural dataset repetitively, we found that there was an error in the representative diameters for grain size classes, but the weight percentage values are correct for the dataset of Phra Thong island. The error was there only with the values of the representative diameters. The grain size classes which were mentioned in

Printer-friendly version

Discussion paper 
the submitted manuscript were $659,329,164,82$ and $41 \mu \mathrm{m}$ respectively which will be changed to $726,364,182,91$ and $46 \mu \mathrm{m}$ respectively in the revised manuscript. NHESSD Hence, the DNN inversion results will be slightly changed in values. We have checked the DNN results with the revised dataset and the results were almost similar with the reported values in the manuscript. The final changes will be done on the revised manuscript. I will also upload the revised and detailed calculated dataset to zenodo repository (https://doi.org/10.5281/zenodo.4075137.). We apologize for the inconvenience caused. I have added the revised dataset as a supplement with this comment.

Please also note the supplement to this comment:

https://nhess.copernicus.org/preprints/nhess-2020-373/nhess-2020-373-AC6-

supplement.pdf

Interactive comment on Nat. Hazards Earth Syst. Sci. Discuss., https://doi.org/10.5194/nhess2020-373, 2020.

Printer-friendly version

Discussion paper 